\title{
DOĞU ANADOLU GÜNEY KAFKASYA KÜLTÜRLERİ
}

IŞIKLI, Mehmet - CAN, Birol, Eds., Uluslararası Doğu Anadolu Güney Kafkasya Kültürleri Sempozyumu, Cilt I - II, Cambridge Scholars Publishing, Newcastle upon Tyne, United Kingdom, 2015. Bu kitap 2 Cilt halinde hazırlanmıştır. I. Cilt: 36 makale ve 402 sayfadan; II. Cilt ise: 39 makale ve 511 sayfadan oluşmaktadır.

\section{SIrrı TIRYAKI“*}
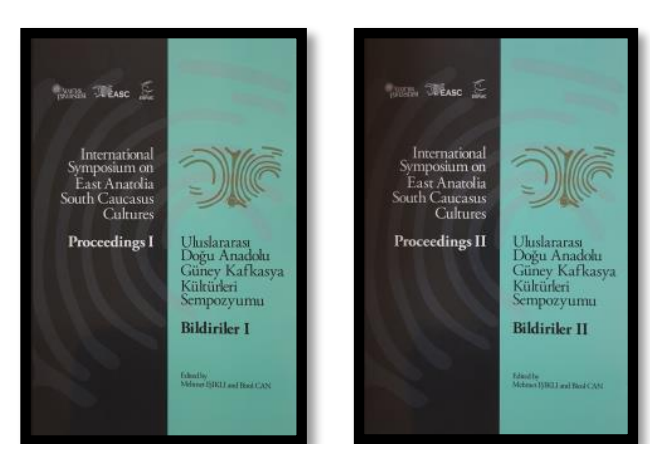

Söz konusu bu çalışma ESRUC (Eurasian Silk Road Universities Consortium) çatısı altında ve Atatürk Üniversitesi ev sahipliğinde 10 - 13 Ekim 2012 tarihleri arasinda gerçekleştirilen "Uluslararası Doğu Anadolu - Güney Kafkasya Kültürleri Sempozyumu'nda" sunulan sözlü bildirilerin tam metinlerinden oluşmaktadır. Doğu Anadolu ve Güney Kafkasya'nın Prehistorik Çağlarından başlayarak Ortaçağ'ına kadar devam eden bütün süreçler ve bu coğrafyalarda insana dair yaşanan gelişmeler kitaptaki makalelerde özgün bir şekilde ele alınmıştır. Söz konusu makaleler Arkeoloji, Sanat Tarihi, Etnoarkeoloji, Tarih ve Coğrafya gibi bilim dallarını kapsamaktadır. 2012 yılında gerçekleştirilen bu sempozyumun yanı sıra Doğu Anadolu ve Güney Kafkasya coğrafyalarının antik dönem serüvenlerinin ele alındığ diğer bir bilimsel faaliyet ise 27 - 29 Ekim 2018 tarihlerinde Atatürk Üniversitesi ve Uzundere Belediyesi'nin katkılarıyla "Tarih Boyunca Anadolu ve Gürcistan İlişkileri Sempozyumu" olmuştur. Gerçekleştirilen

* Dr. Öğr. Üyesi, Bingöl Üniversitesi, Fen-Edebiyat Fakültesi, Tarih Bölümü, sirri_tiryaki@ hotmail.com, ORCID: https://orcid.org/0000-0002-1053-0836 
bütün bu sempozyumlarla, Anadolu ve Kafkasya'nın Prehistorik Çağlarına Orta Çağ'a kadar devan eden kültürel veriler ortaya çıkarılmaya çalışılmıştır.

2 ciltten oluşan kitabın Önsöz kısımları Prof. Dr. Hikmet KOÇAK ve Prof. Dr. Dilaver Düzgün, Giriş yazısı ise kitabın bilimsel editörleri Mehmet IŞIKLI ve Birol CAN tarafından yazılmışıtır. Prof. Dr. Fahri IŞIK tarafından kaleme alınan "Batıyı Yaratan Uygarlık: Anadolu - İon" konulu açılış bildirisi ile Avrupa uygarlığının Anadolu topraklarında doğup geliştiği ifade edilmiştir. Eserin 1. cildinde Doğu Anadolu ve Güney Kafkasya coğrafyalarının Kalkolitik ve Tunç Çağlara dair önemli makaleler yer almaktadır. Kalkolitik Çağ'a ait makaleler, dönemin gündelik yaşam sosyolojisini ve teknolojisini yansıtması açısından kayda değerdir: Christine Chataigner, Makoto Arimura, Ruben Badalyan ve Giulio Palumbi tarafindan kaleme alınan "Neolithic and Chalcolithic in Armenia: New Data / Ermenistan'da Neolitik ve Kalkolitik: Yeni Veriler" isimli makalede Neolitik Çağ'da Ermenistan coğrafyasında basınçla yongalama tekniği kullanılarak yapılan mikrolit aletlerden bahsedilmiş̧ir. Söz konusu bu makalede Kalkolitik Çağ'da bölgede yaygın olarak görülen obsidyen aletlerin yanı sıra Ermenistan'daki kültürel çeşitliliğin nedeninin Yakındoğu ve Kafkaslar gibi yakın coğrafyalarla sürdürülen ticari ve kültürel ilişkiler olduğu da ifade edilmiştir.

Kafkas coğrafyasının önemli bölgelerinden birini oluşturan Nahçıvan coğrafyasının Son Kalkolitik Çağı'na dair verilerin O. H. Hebiullayevin tarafından 1951 yılında gerçekleştirilen kazılarda ortaya çıkarıldığı bunun yanı sıra Kuzey Mezopotamya'ya ait Kalkolitik kültürün Azerbaycan ve Nahçıvan'a kadar yayıldı̆̆ı ve Nahçıvan'daki Halaf, Ubeyd ve Uruk kültürlerine ait tartışmalara ise Veli Bahşaliyev'in "Late Chalcolithic Culture of Nakhchivan and Problems of Caucasian Archaeology / Nahçıvan Son Kalkolitik Kültürü ve Kafkasya Arkeolojisinin Sorunları" isimli makalesinde değinilmiştir. Ali Binandeh ve Aram Kosyan tarafindan kaleme alınan "The Southern Urmia Basin during the Chalcolithic Period / Kalkolitik Dönem'de Güney Urmiye Havzası" isimli makalede Kuzeybatı İran coğrafyasındaki Solduz Vadisi'nde Halaf kültürüne dair herhangi bir buluntunun söz konusu olmadığı ifade edilmiştir. Ancak bu coğrafyada Uruk kültürüne ait çanak çömleklerin tespit edilmesiyle birlikte Güney Urmiye Havzası için yeni bir kronoloji önerilmiştir.

Sempozyum konusu olan sahanın Tunç Çağı'na dair makaleler; Anadolu ve Kafkasya coğrafyalarında Tunç Çağı'nda yaşanan gelişmelere dair okuyucuya önemli fikirler sunmaktadır: Giulio Palumbi "The Role of Pastoral 
Communities of the Upper Euphrates Region in the Expansion of the KuraAraxes Culture / M.Ö. Üçüncü Binyılın Başlarında Malatya Ovası'nda KuraAras Kültürü ve Pastoral Topluluklar" isimli makalesinde Kura-Aras kültürünün yayılımının geleneksel göç hareketlerine dayalı olarak gerçekleştiği şeklindeki yaklaşımlardan vazgeçilmesi gerektiğini ifade etmiştir. MÖ 3. binyıl başlarında Yukarı Fırat Bölgesi'ndeki Kura Aras kültürünün yayılımının tam olarak anlaşılabilmesi için araştırmaların Kura Aras kültürünün merkez bölgesinden Yukarı Fırat'ın siyasi ve ekonomik sürecine kaydırılması gerektiğini ifade etmiştir. Ayrıca Palumbi, Kura Aras kültürünün yayılımında kitlesel göç hareketlerinden ziyade MÖ 3. binyıl başlarında Yukarı Fırat Bölgesi'nde yerleşmiş olan ve beli konularda uzmanlaşmış olan kırsal grupların etkili olduğunu önermiştir. Toby C. Wilkinson tarafindan kaleme alınan "Alternative Economies: The Early Transcaucasian Phenomenon in Structural-Systemic Perspective / Alternatif Ekonomiler: Yapısal-Sistemik Bakış Açısıyla Erken Transkafkasya Fenomeni" isimli makalede ise Erken Transkafkasya fenomenini anlamak için coğrafyanın önemli olduğunu ve bu kültüre mensup insanların, metal kaynakları ile kullanıcıları arasındaki arabulucu konumlarından dolayı kuzey ve güney bölgelerine metal ihraç ettikleri ifade edilmiştir.

Mitchell S. Rothman, "The Changing Organisation of Kura Araxes Culture / Kura Aras Kültürü: Köken ve Gö̧̧” isimli makalesinde Kura Aras kültürünü Erken Transkafkasya, Karaz ve Khirbet Kerak gibi isimlerle tanımlamıştır. Kura Aras kültürünün dağlık coğrafyalara ait bir kültür olduğunu ve bu kültürün anavatanı olarak Güney Kafkasya ve Türkiye'nin kuzeydoğusundaki Kura Aras Nehirlerinin havzaları olduğunu ifade etmiştir. Güney Kafkasya'da Erken Bronz Çăğ'na tarihlendirilmiş (Kura Aras kültürü) yerleşim alanlarında resimlendirilmiş çok az seramiğin ele geçirilmesi gibi konuların yanı sıra on binlerce siyah renkte cilalanmış kil çömlek arasında, resimlerin sadece birkaç düzene çömlekte bulunduğu gibi konular ise Nino Shanshashvili ve George Narimanishvili'ye ait "Painted Pottery of the KuraAraxes Culture from the South Caucasus / Güney Kafkasya Kura-Araks Kültürü'nün Boyalı Seramiği” başlıklı makalede gündeme getirilmiştir. Zviad Sherazadishvili, "Attempt to Determine Origin, Chronology and Function of South Caucasus Trialeti Culture Bronze Rapiers / Güney Kafkasya Trialeti Kültürüne Ait Tunçtan Ince Kllıçların (Meçlerin) Kökeni, Kronolojisi ve İslevini Belirleme Denemesi" makalesinde Güney Kafkasya, Trialeti kültüründeki savaş silahları arasında "Rapirler" in özel bir konuma sahip 
olduğunu ve bu silahların yayılım alanları arasında Anadolu, Güney Kafkasya, Suriye ve Ege dünyasının olduğunu ifade etmiştir. Ayrıca bu silahların ortaya çıkışı ve kronolojisi hakkında çeşitli görüşlerin olduğunu da vurgulamıştır.

Süleyman Çiğdem ve Birol Can'ın “Early Farmers of Erzurum / Erzurum'un ilk Tarımcıları" isimli makalesinde Geç Kalkolitik Çağ'dan itibaren yerleşik hayata sahne olan Erzurum ve çevresinde kazısı yapılan Karaz, Pulur, Güzelova, Sos ve Bulamaç Höyüklerinin yanı sıra henüz daha kazısı gerçekleştirilemeyen birçok yerleşim alanının bulunduğu ve Tunç Çağları boyunca da yerleşime sahne olan bu yerleşim alanlarının geçim kaynakları arasında modern dönemlerde olduğu gibi hayvancılık ve tarımın ön planda olduğu ifade edilmiştir. Kura Aras kültürünün Kafkaslar ve Doğu Anadolu coğrafyasının ötesinden Doğu Akdeniz'deki kıyı ovalarına, Hazar kıyılarından Orta Anadolu platosuna kadar çok geniş bir coğrafyada varlık gösteren bir kültür olduğu, bu kültürün kendine özgü çanak çömlekleri ve ocaklarının olduğu konusu ise kitap editörlerinden Mehmet Işıklı'nın, “The Development of the Kura Araxes Culture in Eastern Anatolia: Problems, Determinations and Suggestions / Kura-Aras Kültürü'nün Doğu Anadolu Bölgesindeki Gelişimi: Sorunlar, Tanımlar ve Öneriler" konulu makalesinde tartışılmıştır.

Eserin 2. cildinde ise Doğu Anadolu ve Güney Kafkasya coğrafyalarının Demir Çağı ve Orta Çağ'ına dair önemli makaleler yer almaktadır. Demir Çağ'1 değerlendiren yazar ve makalelerden; Mahmut Bilge Baştürk "Considerations on the Belief Systems of the Early Iron Age Peoples in Lake Van Basin / Van Gölü Havzası'nda Erken Demir Çăğ Halklarının İnanç Sistemleri Üzerine Düşünceler" isimli makalesinde Erken Demir Çă̆g'nda Van Gölü Havzasında yaşayan halkların ortak dini ritüeller etrafinda birleşebilen topluluklar olduğunu ve bu toplulukların güçlü bir öteki dünya inanışına sahip olduklarını ifade etmektedir. Baştürk, yöre halkında görülen öteki dünyaya dair güçlü bir inanışın varlığını ise mezarlardan elde edilen buluntulara dayandırmaktadır. Ramin Alizadeh'e ait "Urartu Çivi Yazıları Belgelerine Göre Güney Kafkasya 'nın Bazı Küçük Beylikleri:Etiuni, Erikuahi, Uelki, Qu-Albani, Luipruani, Arquqiu / Some Small Principalities of Southern Caucasus According to Urartian Inscriptions: Etiuni, Erikuahi, Uelki, QuAlbani, Luipruani, Arqiuqi" başlıklı makalede Etiuhi ülkesinin MÖ IX yüzyılın sonlarından itibaren Aras Nehrinden kuzeyde Azerbaycan topraklarında kurulan ilk devlet olduğu ve Urartu kralI yazıtlarında bu ülkenin isminin çoğunlukla Etiuhe/ne şeklinde geçtiği ifade edilmiştir. Ayrıca Urartu krali yazıtlarında Erikuahi şeklinde geçen beyliğin yanı sıra Uelki, Qu'Albani, 
Luipruani ve Arqiuqi isimli beyliklerin de Gökçe Gölü havzasında kurulduğu ifade edilmiştir.

Dağlık Doğu Anadolu coğrafyasında güçlü bir devlet olarak ortaya çıkan Urartu Krallığı'nın MÖ 7. yüzyılın sonlarına doğru tarih sahnesinden çekilmesiyle birlikte ortaya çıkan yeni durum ve buna bağlı olan gelişmelerin seyri konusundaki bilgiler sinırlıdır. Bununla birlikte MÖ 9. yüzyılın ortalarından itibaren Urartu Krallığı'nın kuruluşu ile birlikte bölgede ortaya çıkan statükonun yok oluşu, muhtemelen var olan düzenin büyük çapta bozulmasına ve ekonomik düzenin daha da ağırlaşmasına neden olmuştur. Urartu ardılları olarak tanımlanan ve Doğu Anadolu Bölgesi'nde yaşayan halkların tarıma uygun olmayan dağlık ve yüksek alanlarda yaşadığı ve bölgenin daha sonraki sakinleri olan Armenler ile coğrafyanın otlak ve tarımsal alan olarak kullanılması konusunda çatışmaların çıktığı ve bu gelişmelere bağlı olarak bölge sakinleri MÖ 7. yüzyılın sonlarında yerlerini terk etmiştir. Bütün bunların yanı sıra MÖ 550 yılından sonra, İran'da değişen siyasal dengelere bağlı olarak Doğu Anadolu Bölgesi'nde yeni bir egemenlik sürecinin başlaması gibi Urartu Dönemi ve Urartu sonrasında Doğu Anadolu'da yaşanan sosyo-politik gelişmeler Hatice Kalkan'a ait "Van Havzası'nda Post Urartu, Med ve Akhamenid Dönemlerinin Kültürel Tanımı Üzerine / Over the Cultural Identification of Post Urartian, Median and Achaemenid Periods in the Van Basin" isimli makalede incelenmiştir. Altan Çilingiroğlu'na ait "Van Ayanis Kalesi Kazıları Işı̆̆ında Urartu'da Son Gelişmeler / In the Light of Excavations on Van Ayanis Fortress: Recent Developments in Urartu" isimli makalede ise Ayanis Kalesi kazılarında ele geçirilen birçok buluntunun Urartu sanatıyla ilgili önemli bilgiler ortaya koyduğunu ve ayrıca Ayanis'teki tapınağa ait mülklerin varlığından bahsedilmiştir.

Eserin 2. cildinin son bölümünde ise bölgelerin Orta Çağ'ında yaşanan sosyo-politik gelişmeler ele alınmıştır: Sanat Tarihçisi Hamza Gündoğdu tarafindan kaleme alınan "XI.-XVIII. Yüzyıl Kuzeydoğu Anadolu Türk Mimarisinde Geleneksel ve Yerel Üslup Uzantılarl / Extensions of Traditional and Local Styles in Northeastern Anatolia: Turkish Architecture in the XIXVIIIth Centuries " isimli makalede kuzeydoğu Anadolu'nun önemli yerleşim alanlarından Ani, Iğdır ve Doğubayazıt'taki mimari yapıların 11. ve 18 . yüzyıllarda taştan yapıldığından ve tonoz örtü biçimleri ile birlikte, bu yapıların dış görünümlerini zenginleştiren, geometrik desenli süs unsurlarının kullanıldığından bahsedilmiştir. Ayrıca Roberto Bixio ve Andrea de Pascale'nin kaleme aldığı "Defensive Devices in Ancient Underground Shelters: Comparison among the Sites of Aydintepe, Ani, Ahlat and Cappadocia in Turkey / Eski Yeraltı Barınakları'ndaki Savunma Düzenekleri: 
Doğu Anadolu Yerleşimleri (Aydintepe, Ani, Ahlat) ve Kapodokya Arasinda Karşılaştırma" isimli makalede ise Türkiye'de Antik Dönemlere ait insanlar tarafından oyulmuş çeşitli türlerde çok sayıda yeraltı yapılarının mevcut olduğu ifade edilmiştir. Devamında 1991'den günümüze kadar Centro Studi Sotterranei (Yeraltı Çalışmaları Merkezi)'nin İtalyan uzmanlarının, Türkiye'nin kuzey-doğusunda Bayburt yakınlarındaki Aydıntepe kazı alanın da bulunan yapıların büyük bir kısmını ziyaret ettiği ve Ani (Kars), Ahlat (Bitlis) ve Kapadokya (Nevşehir)'daki yeraltı yerleşim alanlarında kapsamlı araştırmalar yürüttükleri de dile getirilmiştir. Söz konusu bu yerleşim alanlarının her birinde barınma, ibadet, mezar, su kanalı, transit geçiş ve savaş, istila, kuşatma, yağma ve haydutluktan korunmak için sığınak gibi çeşitli şekillerde kullanılan kayaya oyulmuş yapıların belgelendiği de gündeme getirilmiştir.

Anadolu ve Kafkas coğrafyaları arasındaki ilişkilerin Eski Çağ Tarihi sınırları içerisindeki derinliği Neololitik Çağ'a kadar inmektedir. Bu ilişkilerin kurumsallaşması Kalkolitik Çağla başlar, Tunç Çağlarına gelindiğinde ise her iki coğrafyada ortak kültürler etkili olmaya başlamıştır. Ve bu ilişkiler MÖ 1500 lü yıllara kadar devam etmiştir. Tarih, Arkeoloji, Sanat Tarihi gibi modern bilimlerin ortak referans noktaları geçmişteki yaşanmışlıkları olabildiğince en nesnel ya da yalın haliyle modern insana ulaştırmaktır. Tarihsel kronoloji kapsamında Kalkolitik Çağ'dan Orta Çağ'a kadar Anadolu ve Kafkasya coğrafyalarında geçmişte kalan yaşanmışlıkları konu edinen "Uluslararası Doğu Anadolu Güney Kafkasya Kültürleri Sempozyumu", isimli kitap çalışmasını bu bağlamda ele almalıyız. Çünkü gerek "Uluslararası Doğu Anadolu Güney Kafkasya Kültürleri Sempozyumu" gerekse sempozyumda sunulan bildirilerin kitaplaştırılmasının temelinde yatan ana düşünce Anadolu ve Kafkas coğrafyaları arasındaki yaşanmışlıkları modern insana ulaştırmak ve bu konularda bilinirlilik oluşturmak temel amaç olmuştur. Ayrıca bu kitap çalışması için "Tarihin arka odasında Anadolu ve Kafkaslar arasındaki kültürel birlikteliğin ortak ürünü” şeklinde bir ifade kullanmak sanırım yerinde bir tanımlama olur.

Kitap sadece içeriğiyle değil, aynı zamanda görsel açıdan da çarpıcı niteliklere sahiptir. Kitapta yer alan makalelerin tamamı yazıldığı konularda özgün ve dikkat çekici bilgilere sahip olmakla beraber aynı zamanda araştırmacılar için önemli bir başvuru kaynağı niteliğindedir. Gerek sempozyum aşaması gerekse sempozyumda sunulan bildirilerin kitaplaştırılması sürecinin zorlu ve büyük emeklerle yürütüldüğü aşikardır. Bütün bunlarla birlikte eserde yer alan makaleler arkeoloji ve sanat tarihi olmak üzere iki ayrı bölüm şeklinde tasnif edilmiş olsaydı, bilimsel ve konusal bütünlük açısından çok daha faydalı olurdu kanısındayım. Eserin 1. cildinde 
Kalkolitik Çağ başlığı altında yer alan makalelerin tamamının Kafkas coğrafyasıyla ilgili olması ve Anadolu'nun Kalkolitik Çağı'na dair makalelerin yer almaması göze çarpan hususlar arasında yer almaktadır. Ek olarak, yazım dili İngilizce olan makaleler Türkçe çevirileriyle birlikte yayınlanmış olsaydı eserin Türkiye'de daha fazla okuyucu kitlesine ulaşması adına daha anlamlı katkılar sağlayacaktı. Bundan sonrası için Anadolu ve Kafkas coğrafyalarının Eski Çağ Tarihine dair bu tarz bilimsel toplantıların planlanması, hayata geçirilmesi ve yazıya dökülmesinin, bölgelerin Prehistorik geçmişlerinin gün 1şığına çıkarılması adına oldukça fayda sağlayacağı kanaatindeyim. 